\title{
Burmese Pythons in South Florida Scientific Support for Invasive Species Management
}

\section{A Rapidly Growing Problem}

Burmese pythons (Python molurus bivittatus) are popular pets in the United States because of their attractive color pattern, reputed docility, and the allure (for some) of owning a giant snake. According to the U.S. Fish and Wildlife Service, approximately 99,000 Burmese pythons were imported to the United States between 1996 and 2006 (compared to only 17,000 between 1970 and 1995). The species is classified by the World Conservation Union as "near threatened" in its native range in Southeast Asia due to exportation for the pet trade and hunting for skins. Thousands of pythons are also captive bred each year in the U.S. for sale as pets. Burmese pythons sell at reptile trade shows for as little as $\$ 20$, and at pet stores for \$65-80. An inexperienced snake keeper who takes home a 50 -centimeter (20-inch) hatchling is, within a year, responsible for a brawny 2.4-meter (eight-foot) predator. Unable to handle their giant snakes, and unable to find new homes for them, some owners illegally release them into the wild. Released and escaped Burmese pythons are now breeding in the wild, and their growing numbers may result in dire consequences for native wildlife and ecosystems in South Florida.

Native to Southeast Asia, Burmese pythons are an exotic (nonnative) species in South Florida. They are also an invasive species, which means that they are not constrained by natural factors as much as they were in their native habitat. Invasive species have the potential to harm their new environments. The release of Burmese pythons in South Florida is especially troublesome because the subtropical climate and the vast undisturbed habitats of the Everglades enable the species to

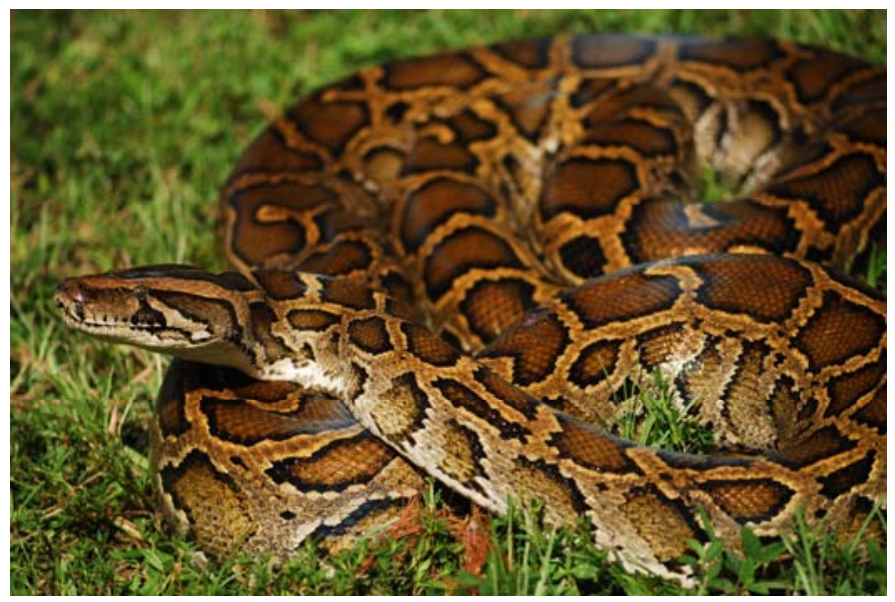

Burmese python (Python molurus bivittatus)

Photo: Wellington Guzman, University of Florida

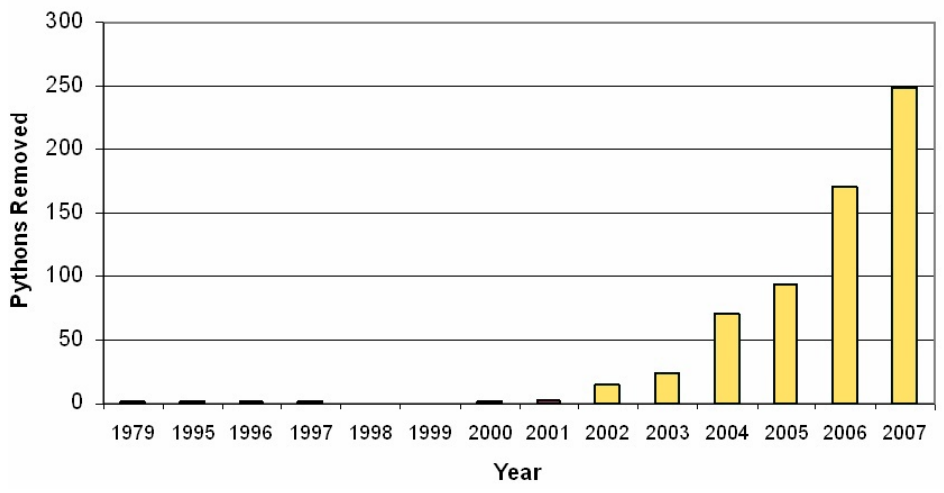

Figure 1. Annual number of Burmese pythons removed from the population (captured and removed or found dead) in Everglades National Park and vicinity, 1979-2007.

Source: U.S. National Park Service

thrive. Other large nonnative snakes-such as the common boa (Boa constrictor), green anaconda (Eunectes murinus), yellow anaconda (Eunectes notaeus), and reticulated python (Python reticulatus) — have been observed in the wild in South Florida, but only Burmese pythons and common boas are known to be breeding. Boas have been breeding since approximately 1970 in the Charles Deering Estate at Cutler, southern Miami-Dade County. Boas have also been reported elsewhere in South Florida, but without evidence of breeding.

Burmese pythons were first reported as established in Everglades National Park (ENP) by Meshaka et al. (2000), based in part on specimens collected on the Main Park Road in the mid-1990s. Since then, the number of Burmese pythons captured or found dead in and around ENP has increased dramatically (Figure 1). From 2002 (when the numbers first began to climb) to 2005, 201 pythons were captured and removed or found dead. In 2006-2007 alone, that number more than doubled to 418 . These totals include pythons that were killed by farm machinery or removed after encounters with workers during water management and ecological restoration projects. Although the size of the wild population is not known, it has been estimated to number in the thousands (Snow et al. 2007b). Burmese pythons have been seen with increasing frequency in and around ENP and on lands managed by South Florida Water Management District (SFWMD) along the park's eastern boundary; they also have been observed in new and more remote locations (Figure 2). This suggests a far broader invasion than was initially thought and one that appears to be expanding. 


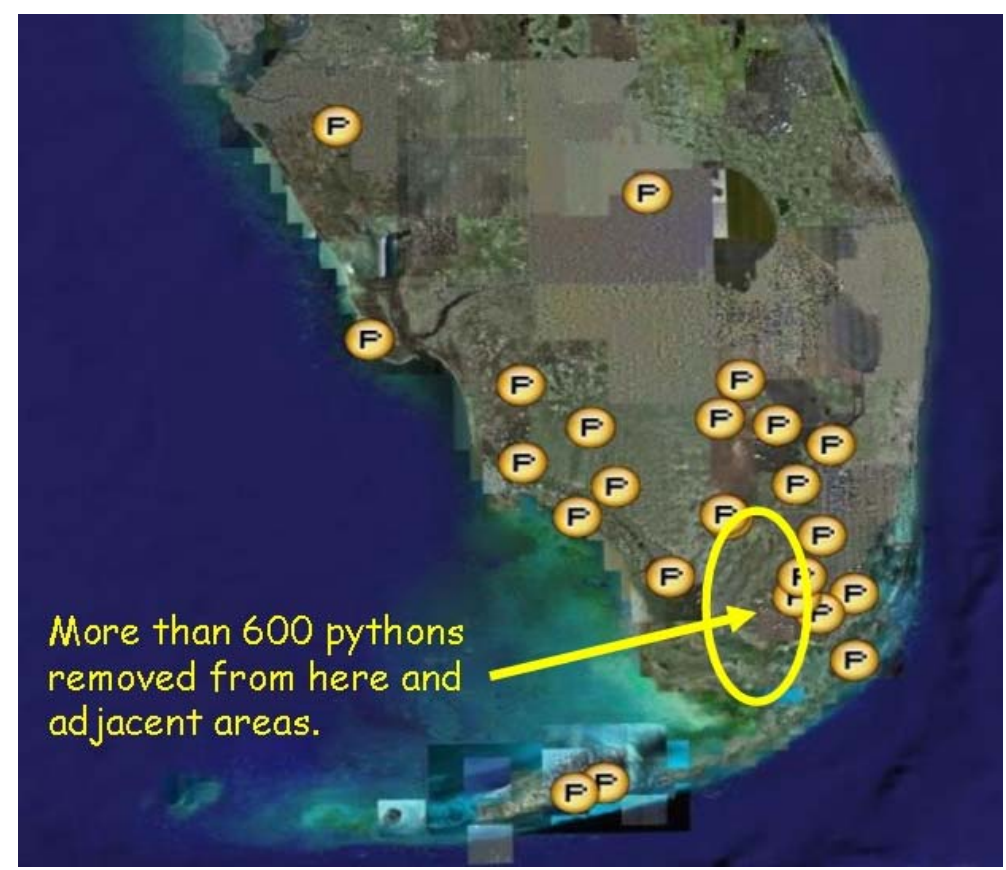

Figure 2. Locations of Burmese pythons removed or observed in South Florida from the mid-1990s to 2007. Each dot represents one or more exotic constrictors that have been identified as Burmese pythons (with a few exceptions, such as a snake in the lower Florida Keys that was first reported as a Burmese python but has since been identified as a common boa). Burmese pythons have been observed at three main locations in ENP: (1) along the Main Park Road in the saline and freshwater glades, and mangroves between Pay-hay-okee and Flamingo; (2) in the greater Long Pine Key area (including Hole-in-theDonut); and (3) in the greater Shark Valley area along the Tamiami Trail (including L-67 Ext.). They have been observed on the eastern park boundary, especially in the C-111 Project Basin and other canal levees. Recently pythons have been observed in remote areas such as the mangrove backcountry, the 18-mile stretch leading to the Florida Keys, and Key Largo.

Source: U.S. National Park Service

As both predators and competitors, Burmese pythons pose a threat to endangered wildlife in South Florida. A growing wild population of pythons has the potential to create a major ecological problem in ENP and threaten successful restoration of the greater Everglades (National Research Council 2005). Pythons' rapid and widespread invasion is facilitated by aspects of their natural history such as diverse habitat use, broad dietary preferences, long lifespan (15-25 years), high reproductive output, and ability to move long distances. Burmese python hatchlings are larger than hatchlings of native species and are less susceptible to predators. These multiple advantages may allow pythons to compete with native snakes and other predators for food, habitat, and space.

Of particular concern is the spread of pythons to biologically vulnerable areas such as the Florida Keys. Because Burmese pythons are excellent swimmers and can travel long distances in water, the many creeks and canals separating the Keys should not inhibit python movement. In fact, pythons have already been found on Key Largo, where dietary analysis established that the endangered Key Largo woodrat (Neotoma floridana smalli) is among their prey. Burmese pythons are known to frequent wading bird colonies in their native range and, in South Florida, two wading bird species of special concern (limpkin (Aramus guarauna) and white ibis (Endocemus albus)) are known python prey. Other threatened and endangered bird species may be at risk. Moreover, the overlap in diet suggests that the state and federally threatened indigo snake (Drymarchon couperi) may have a fierce competitor for prey (Reed 2005).

Human safety is also a concern. There is no evidence that wild Burmese pythons hunt humans; however, on several occasions large captive Burmese pythons have killed their owners. Perhaps more importantly, large snakes may stretch across roads, posing a hazard to motorists.

\section{Reproduction}

On May 17, 2006, the first python nest was discovered in South Florida (in ENP), confirming that pythons are breeding in the wild. Pythons of both sexes are believed to reach sexual maturity at a length of around 2.6 meters (8.5 feet) (Lederer 1956; Pope 1961). Mating in ENP occurs between December and April. Males locate females by detecting pheromones (chemicals secreted by one animal to send a message to others of the same species). Breeding aggregations of one female and several males are commonly formed. Females lay eggs in May and June, and remain coiled around the clutch until hatching occurs in July and August. In a sample of eight clutches discovered in South Florida (one nest and seven pregnant females), the average clutch size was 36 eggs, but pythons have been known to lay as many as 107 eggs (Wall 1921). A recently captured adult female in ENP was found to be carrying 85 developing eggs.

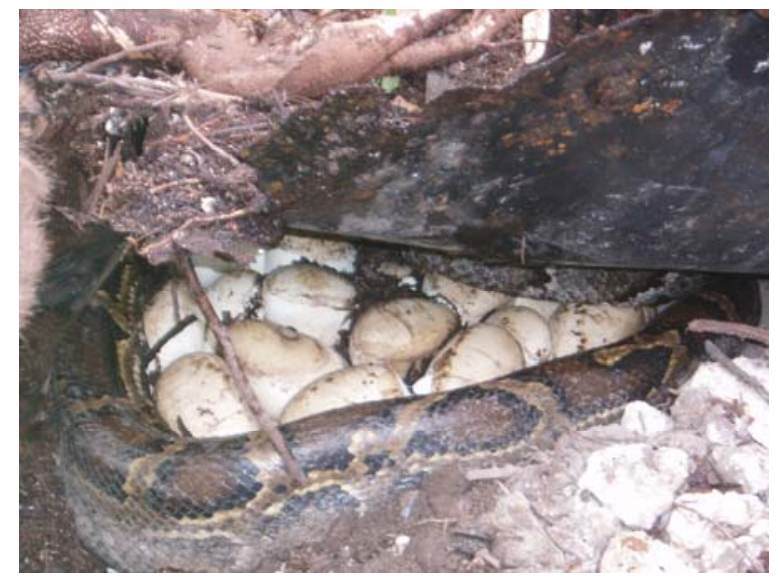

First python nest found in Everglades National Park Photo: Shona Wilson, University of Florida 


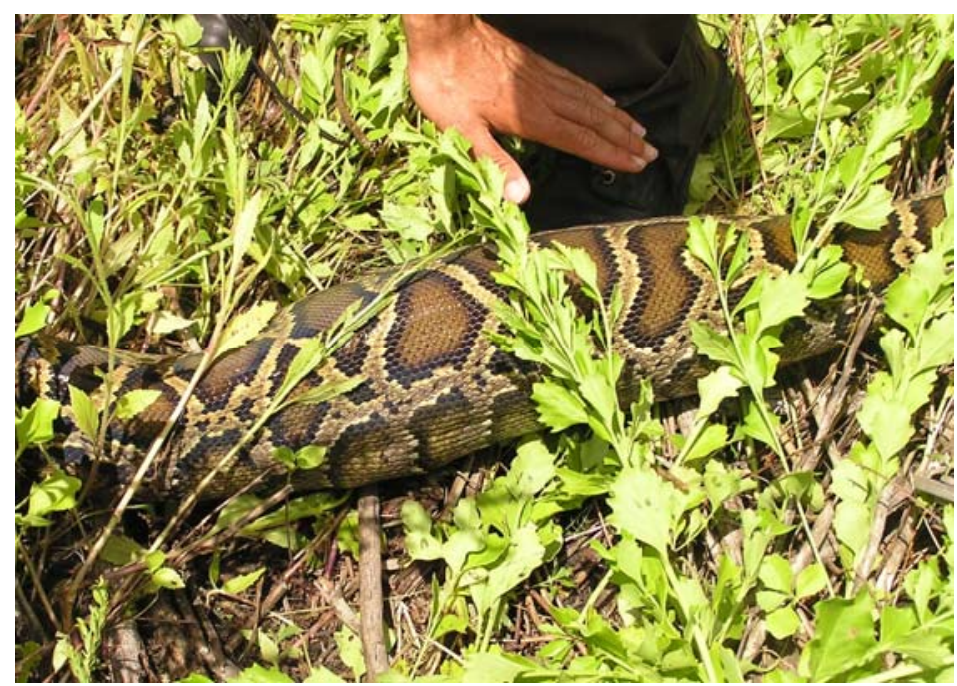

Burmese python with a bulge from a recent feed

Photo: Mike Rochford, University of Florida

\section{Size and Appearance}

The Burmese python is one of the largest snakes in the world: it reaches lengths of up to seven meters (23 feet) and weights of over 90 kilograms (almost 200 pounds) (Ernst and Zug 1996; Minton and Minton 1973). The largest python found thus far in the Everglades was 4.9 meters (16 feet) long and weighed 68.9 kilograms (152 pounds). Hatchlings range in length from 50-80 centimeters (19-31 inches) and can more than double in size within the first year.

Burmese pythons are light colored with dark brown blotches bordered in black, and a pale belly. They grow much longer and heavier than any of Florida's native snakes (the largest is the indigo snake which grows to 8.5 feet). Figure 3 compares the Burmese python to some native snakes that are sometimes misidentified as pythons.

\section{Python Science Support Team}

The University of Florida is collaborating with the United States National Park Service (USNPS), United States Geological Survey (USGS), United States Fish and Wildlife Service (USFWS), South Florida Water Management District (SFWMD), and Davidson College to investigate python impacts in South Florida ecosystems and develop tools for controlling pythons. This Python Science Support Team (PSST) formed in response to an invasive reptile management workshop in July 2005 and a follow-up workshop in March 2007. High priority items identified by workshop participants included determining the status and extent of the python population, investigating movements and habitat use, and refining methods to estimate potential impacts and to capture and remove pythons.

To address workshop recommendations, the PSST developed a collaborative research and management program with funding provided by USGS, USNPS, USFWS, and SFWMD.

The Python Science Support Team is focusing on the following research and management efforts in South Florida:

- Radiotelemetry

- Capture and removal

- Trap design and development

- Diet analysis

- Thermal research

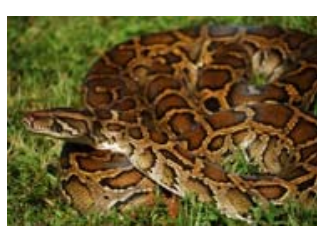

Burmese pythons have a distinctive color pattern (light with dark brown blotches), and more rectangular-shaped heads than rattlesnakes, cottonmouths, and water snakes. Large pythons are identifiable by their longer length (up to $7 \mathrm{~m} / 23 \mathrm{ft}$.) and heavier body than native snakes.

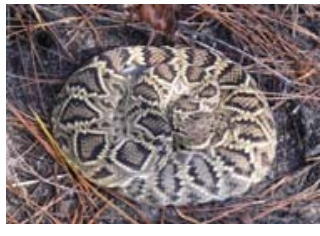

The eastern diamondback rattlesnake (Crotalus adamanteus) reaches lengths of up to $2.1 \mathrm{~m}$ (7 ft.) It has a heavy body like the Burmese python, but a triangularshaped head and an unmistakable yellowand-brown diamond pattern along its back.

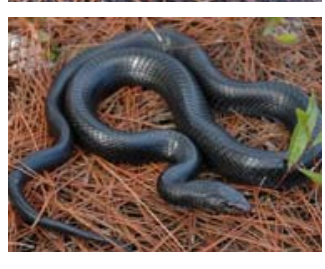

The indigo snake (Drymarchon couperi) can grow to over $2.4 \mathrm{~m}$ (8 ft.). Its large iridescent black scales appear bluish in certain light. The indigo is harmless to humans and is classified as a threatened species due to overcollecting and habitat destruction.

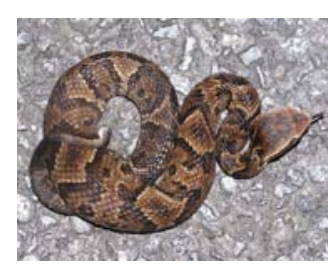

The Florida cottonmouth (Agkistrodon piscivorus conanti) averages about $1 \mathrm{~m}$ (3 ft.) in length, but may grow up to $1.8 \mathrm{~m}$ (6 ft.). It varies in color from banded to solid black, brown, or reddish. It has a large triangular head and a dark stripe on the cheek that runs through the eye.

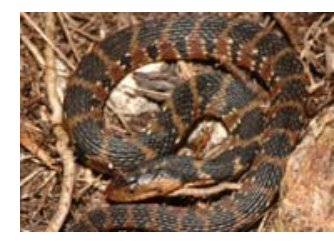

The Florida banded water snake (Nerodia fasciata pictiventris) varies in color from reddish-and-black to mostly black. It can reach $1.5 \mathrm{~m}$ (5 ft.) in length and may be mistaken for the venomous cottonmouth.

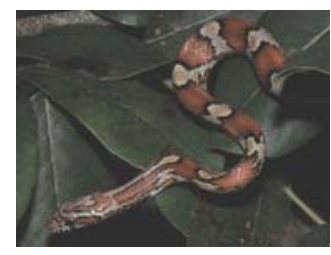

The corn snake, or red rat snake (Elaphe guttata guttata), averages $0.9 \mathrm{~m}$ (3 ft.) in length, and can reach a length of $1.8 \mathrm{~m}$ (6 ft.). It is conspicuous and commonly seen in residential areas.

Figure 3. Comparison of the Burmese python to some native snakes of Florida. Photos: Shona Wilson (eastern diamondback rattlesnake) and Mike Rochford (all others), University of Florida Source: Carmichael and Williams 2006 


\section{Radiotelemetry}

University of Florida researchers are using radiotelemetry to determine how pythons are using the habitat and the extent and timing of their movements. This method is also used to find groups of pythons during the breeding season (called "breeding aggregations"). Since December 2005, 17 adult pythons have been captured and surgically implanted with very high frequency (VHF) radio transmitters in ENP and on lands owned by SFWMD. Pythons are tracked daily for a few days after release, and then tracked by plane once a week. To reduce observer influence on python behavior, researchers locate snakes primarily by triangulation (going to three separate locations, marking each point in a global positioning system (GPS), and taking a compass bearing on the signal of the transmitter). Snakes are tracked on the ground during the breeding season to make sure they are healthy and to locate breeding aggregations.

\section{“Judas Snakes"}

"Judas snakes" are telemetered pythons that lead researchers to other pythons, which are then captured and

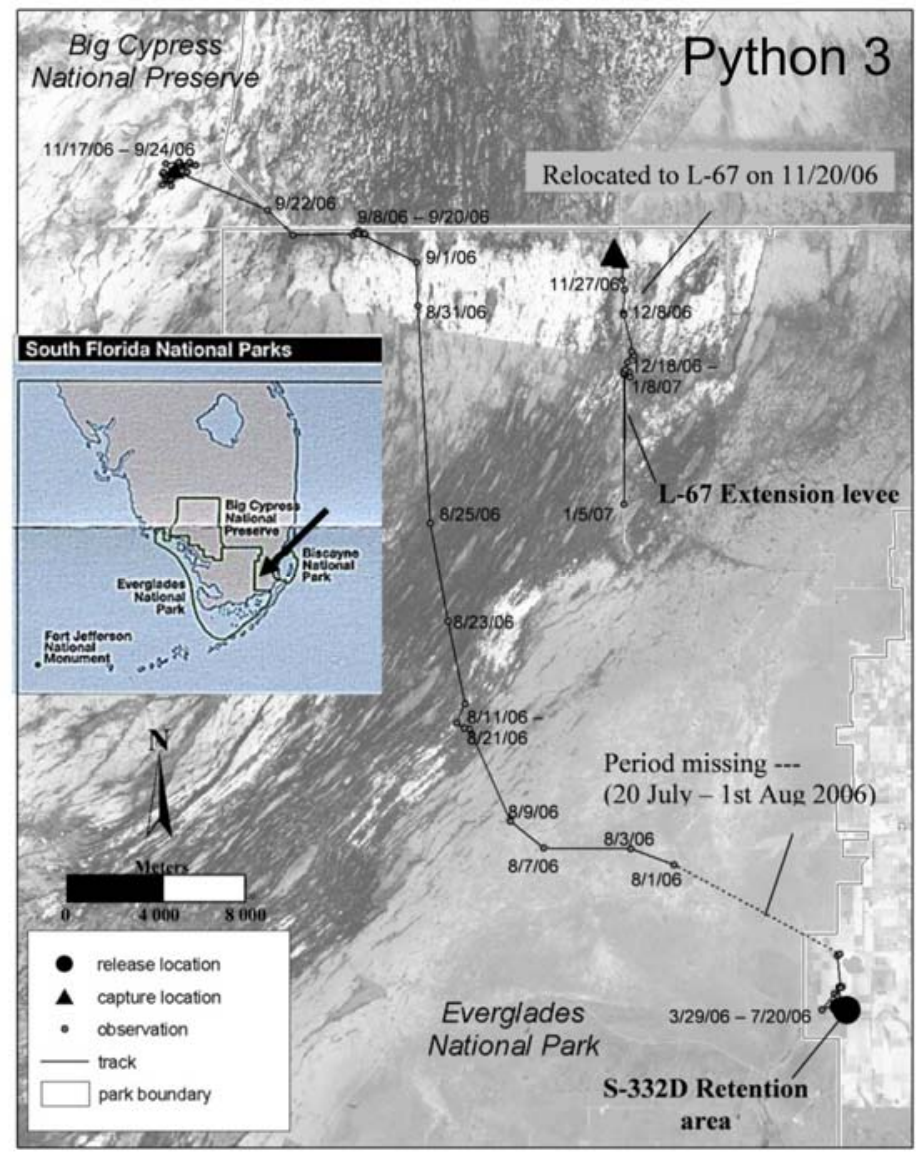

a.

Figure 4. Movements of two telemetered pythons that were captured near the L-67 levee and released in the SFWMD S-332D Retention area. a) Python 3 (male, $3.5 \mathrm{~m} / 11.5 \mathrm{ft}$.) made small movements from 3/29/06 until 7/20/06 when it began a journey of $69.8 \mathrm{~km}$ (43 miles) toward its original capture area, then farther north near the Miccosukee Indian Reservation. Due to concern that it was too close to homes, python 3 was relocated to L-67 Extension levee on 11/20/06; it remained in this area until 1/8/07.

b) Python 5 (female, $4.6 \mathrm{~m} / 15.1 \mathrm{ft}$.) was tracked starting on 6/1/06. It made small movements until 7/14/06 when it moved out of the Retention area and was next located in ENP on 8/3/06. It moved $56.0 \mathrm{~km}$ (35 miles) to arrive at its original capture location near Pa-hay-okee hammock on 9/25/06, and remained in that area for the rest of the study.

Source: University of Florida
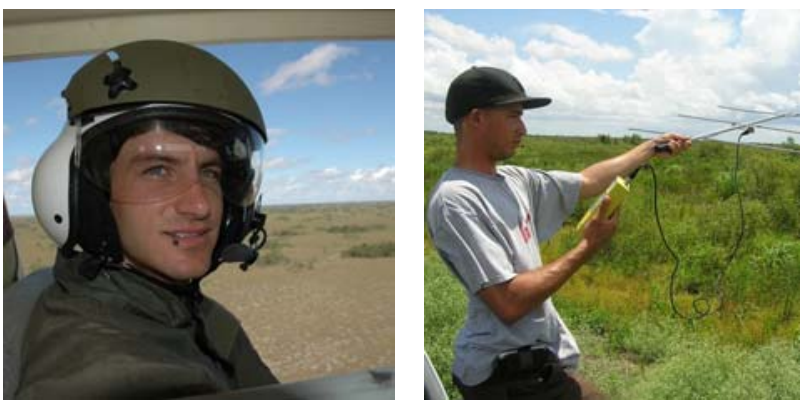

Radio tracking pythons by air and by land

Photos: Matthew Brien and Mike Rochford, University of Florida

euthanized. In the 2006 breeding season, three snakes (one female and two males) were found in association with 15 "new" pythons, and in 2007, two male pythons led to 10 additional snakes. Of the 25 snakes discovered by this method in two years, 19 were captured and removed, and the other six escaped before capture was possible. Following a telemetered female also led to the discovery of the first nest, which confirmed the existence of a breeding population in ENP.

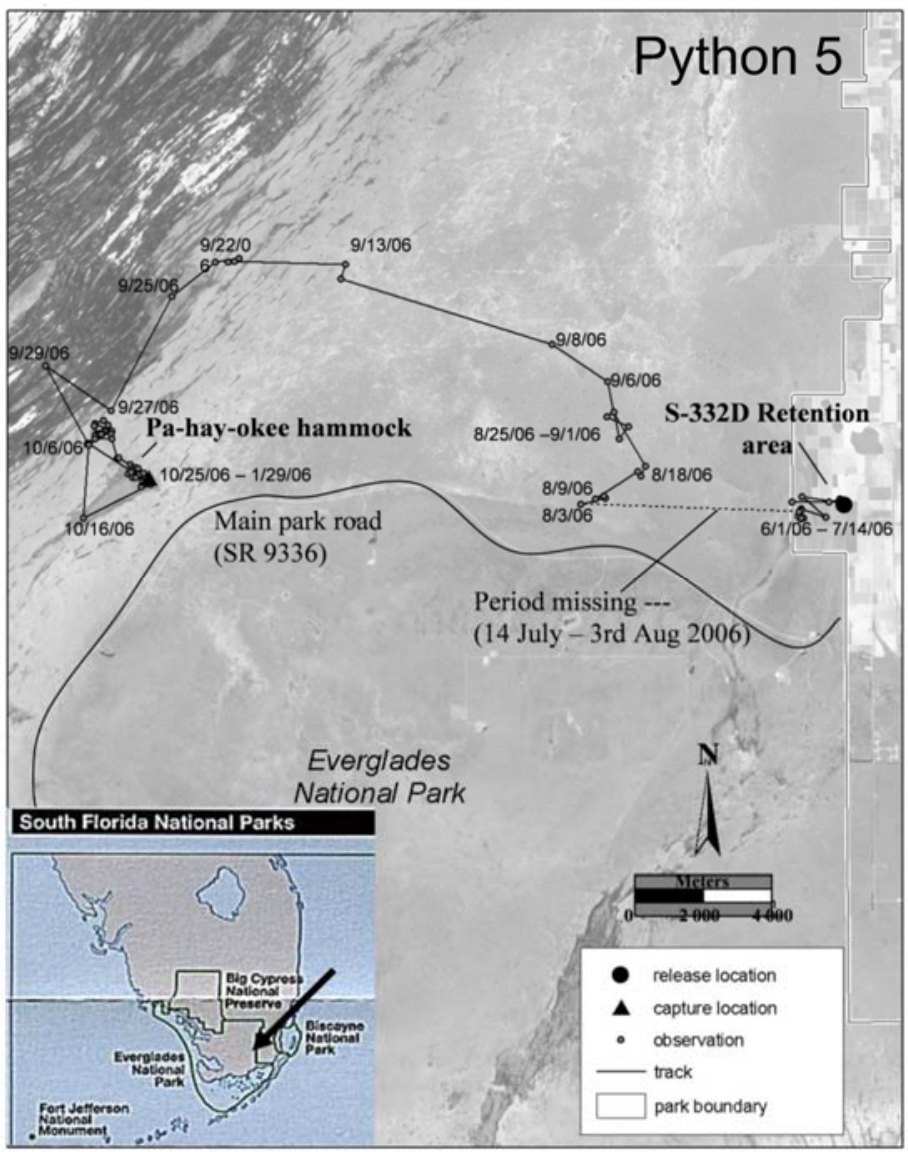

b. 


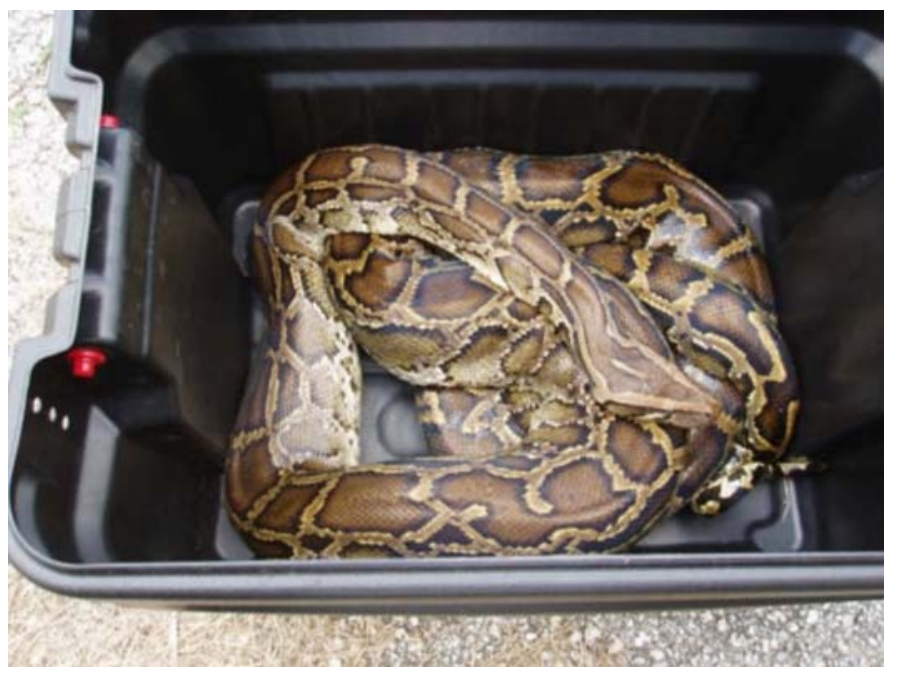

Captured Burmese pythons are removed from the wild and turned over to the National Park Service.

Photo: Jemeema Carrigan, University of Florida

\section{Movement and "Homing"}

Initial results based on radiotelemetry demonstrate that female pythons make few long distance movements throughout the year, while males roam widely in search of females during the breeding season (December-April). In ENP, telemetered snakes moved into habitats away from the road edges where they had been captured and into areas with higher elevation (i.e., tree islands and rock outcrops). A number of relocated pythons have demonstrated a "homing" ability: after being released far from where they were captured, they returned long distances (up to 78 kilometers/48 miles) in only a few months (Figure 4). Homing was observed both in ENP and on SFWMD lands during the non-breeding season (wet season). These individuals moved rapidly (up to seven kilometers/four miles in three days) when surface water was present. Such large-scale movement and apparent ability to "home" has not been documented in previous studies of Burmese pythons. These findings suggest that pythons searching for a suitable home range have the potential to colonize almost any area in South Florida.

\section{Capture and Removal}

The military analogy of "knowing your enemy" captures the goal of the research projects described above. When researchers know where Burmese pythons are located, what types of habitats they use, and how they move, capture and removal efforts become more effective. When pythons are captured, they are euthanized by USNPS personnel. All python nests found in South Florida are also destroyed.

In addition to radiotelemetry, pythons are located by driving roads and walking trails and canal berms. The PSST is investigating other innovative strategies to locate and remove pythons, such as isolating the chemical cues (pheromones) that pythons use to attract each other during the breeding season. Once identified, pheromones can potentially be used to lure pythons into traps. Trained dogs also are being evaluated for their effectiveness at sniffing out snakes.

\section{Trap Design and Development}

The SFWMD, USNPS, USFWS, and USGS are funding two projects in 2008-2009 to design, implement, and evaluate python traps. Informed by past experience battling invasive brown tree snakes on Pacific Islands (Colvin et al. 2005), these projects will apply research findings on distribution, abundance, diet, movements, and habitat use to determine how to design, deploy, and bait traps. Traps will be deployed at sites on north Key Largo, in ENP, and on SFWMD lands in the southern Everglades, and will be checked daily. Results will be synthesized with incoming information from experiments and monitoring, such as data on diet and patterns of movement and habitat use.

\section{Diet Analysis}

Burmese pythons are generalist predators that consume a wide variety of mammal and bird species, as well as reptiles, amphibians, and fish (Snow et al. 2007a). Like other constrictors, the Burmese python seizes prey with its teeth and then wraps its body around the animal and kills it by constriction. Pythons in Florida have consumed prey as large as white-tailed deer (Odocoileus virginianus) and adult American alligators (Alligator mississippiensis) (Snow et al. 2007b). As Burmese pythons expand their range in South Florida, it becomes increasingly important to learn what they are eating in order to assess their impact on native fauna and to predict what species are at risk.

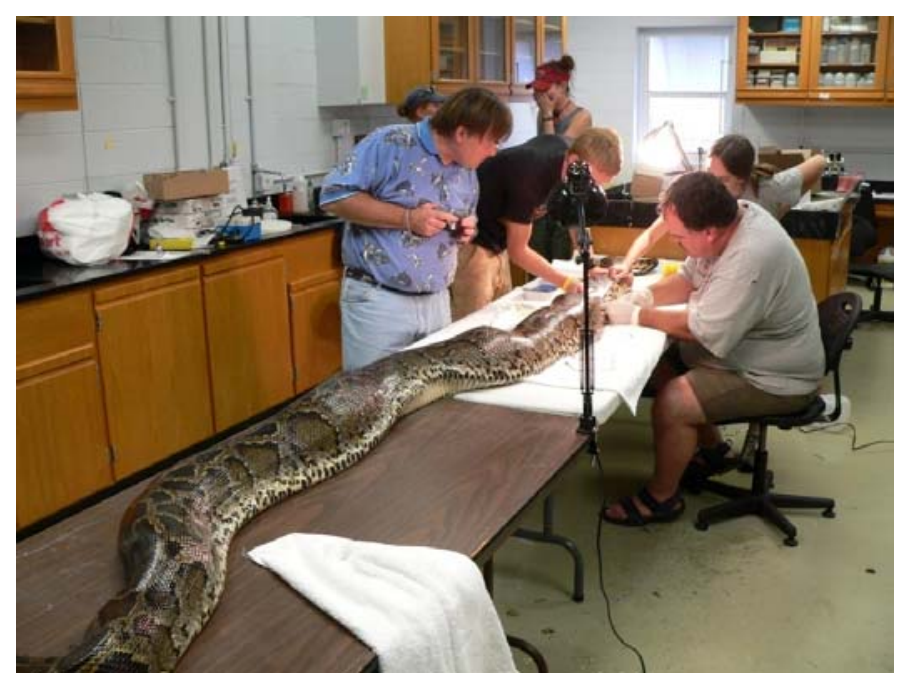

Surgically implanting a radio transmitter in a Burmese python Photo: Tony Mills, Savannah River Ecology Laboratory 
Table 1. Prey species found in the digestive tracts of Burmese pythons collected and examined in Florida (Modified from Snow et al. 2007a).

\begin{tabular}{l} 
Mammals \\
Rabbit (Sylvilagus sp.) \\
Hispid cotton rat (Sigmodon hispidus) \\
Cotton mouse (Peromyscus gossypinus) \\
Gray squirrel (Sciurus carolinensis) \\
Fox squirrel (Sciurus niger) \\
Domestic cat (Felis catus) \\
Raccoon (Procyon lotor) \\
Old world rats (Rattus sp.) \\
Virginia opossum (Didelphis virginiana) \\
Bobcat (Felis rufus) \\
Round-tailed muskrat (Neofiber alleni) \\
Rice rat (Oryzomys palustris) \\
White-tailed deer (Odocoileus virginianus) \\
Key Largo woodrat (Neotoma floridana smalli) \\
\hline Birds \\
Pied-billed grebe (Podilymbus podiceps) \\
Limpkin (Aramus guarauna) \\
White ibis (Eudocimus albus) \\
American coot (Fulica american) \\
House wren (Troglodytes aedon) \\
Domestic goose (Anser sp.) \\
\hline Reptiles \\
American alligator (Alligator mississippiensis) \\
\hline
\end{tabular}

National Park Service personnel euthanize captured pythons, and University of Florida researchers analyze the contents of their digestive tracts. Prey species are identified by bones, teeth, and hair. The team documented the first occurrence of white-tailed deer predation in 2006. Fourteen species of mammals, five species of birds, and one species of reptile have been found in the guts of pythons collected and examined in Florida (Snow et al. 2007a; Table 1). This includes one endangered species, the Key Largo woodrat (Neotoma floridana smalli); one threatened species, the American alligator (Alligator mississippiensis); and two species of special concern, the limpkin (Aramus guarauna) and the white ibis (Endocemus albus).

Given the diverse dietary habits of the Burmese python, it is possible that other state and federally endangered or threatened species in Florida may be at risk as prey. In addition to the Key Largo woodrat, protected species believed to be at risk include the Florida panther (Puma concolor coryi), mangrove fox squirrel (Sciurus niger avicennia), Key Largo cotton mouse (Peromyscus gossypinus allapaticola), wood stork (Mycteria Americana), Cape Sable seaside sparrow (Ammodramus maritiumus mirabilis), and American crocodile (Crocodylus acutus).

\section{Thermal Research}

Thermal research provides detailed data that would otherwise be difficult to obtain due to the remote location of most free-ranging pythons. The PSST is surgically implanting pythons with temperature-sensitive data loggers that record body temperature every 30 minutes; pythons are tracked using radiotelemetry as described above. Additional data loggers are set to record environmental temperatures on land and in the water. Biophysical snake models (copper pipes about the same diameter and painted to absorb the same amount of solar radiation as live snakes) are also monitored to compare to the temperatures of live pythons.

Continuous measurements of snake and environmental temperatures allow researchers to determine when snakes are active and what microhabitats they are using. For example, examination of body temperature plots for three pythons in November 2006 demonstrates that the snakes typically emerged to bask each morning when environmental temperatures were favorable (Figure 5). During the evening, the pythons' body temperatures were well above what they would have been in the open air, indicating that they stayed under water or in sheltered microhabitats. These data on microhabitat use can be applied by researchers and managers to determine the best times to sample or capture pythons.

Temperature data can also provide insight into python feeding frequencies. Because reptiles' metabolic rates are dependent on temperature, mathematical models can predict the number and type of prey items a snake needs. Similar models for eastern diamondback rattlesnakes (Crotalus adamanteus) found that to meet basic maintenance costs, rattlesnakes must consume two food items equal to $30 \%$ of their body mass each year (Dorcas and Willson in press). When the python models are run, they will provide estimates of predation levels to better estimate the predatory impact of pythons on native fauna.

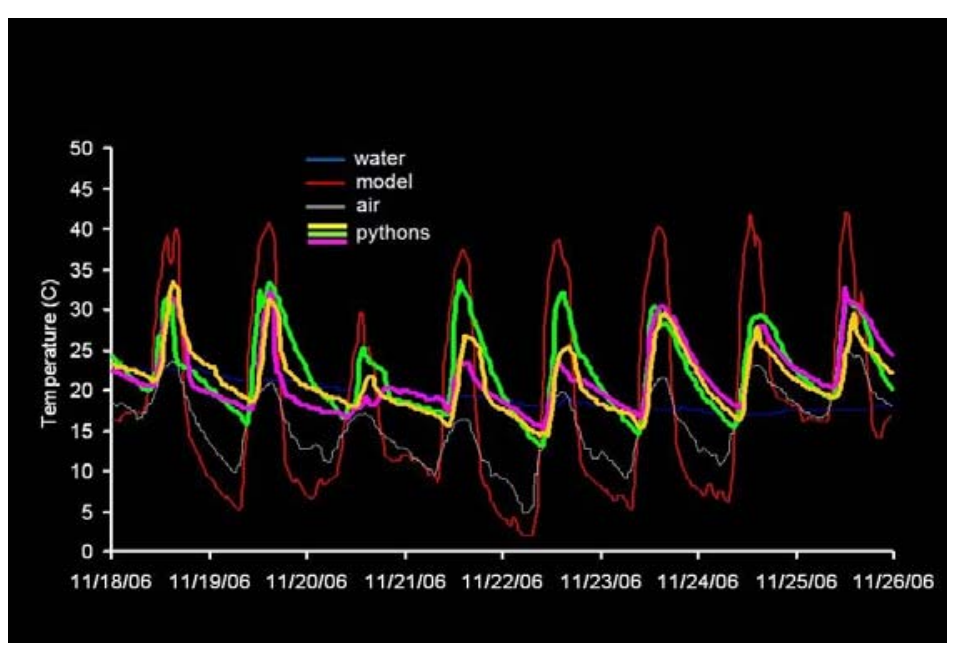

Figure 5. Body temperature of three Burmese pythons in Everglades National Park, November 2006, plotted with air temperature, water temperature, and temperature predicted by biophysical snake models. Source: Davidson College 


\section{Management Priorities}

Priorities for invasive snake management include prevention, eradication, containment, and reduction. To prevent the release of pets, we must promote responsible pet ownership through education, limiting ownership, and providing disposal sites for unwanted animals. Unfortunately, it is too late to prevent the invasion of Burmese pythons and possibly other species of large constrictor snakes. Dealing with established species requires that we understand their extent, behavior, potential ecological impacts, and how to remove them. The research described in the preceding pages is providing answers to these critical questions.

Eradication of invasive snakes is most feasible when intervention is early and when the area is small, isolated, and accessible. Priority areas for eradication include the Florida Keys (because of their ecological vulnerability) and Deering Estate (to eliminate another potentially destructive nonnative species, Boa constrictor). When eradication is not possible, containment and reduction are realistic management goals.

To effectively remove invasive snakes, the Python Science Support Team will continue to research and develop traps and deployment methods. Radiotelemetry and thermal research will be continued in concert with trapping efforts to enable managers to identify areas and times of snake activity. "Judas snakes” play an important role by leading researchers to additional pythons to capture and remove. Continuous synthesis and integration of data into the containment and control program will help to prevent the further spread of invasive exotic snakes throughout South Florida.

\section{Exotic Reptiles and the Law}

Releasing any exotic wildlife in Florida is a first-degree misdemeanor with a penalty of up to one year in prison and a $\$ 1,000$ fine. Further regulatory measures went into effect in 2008 to limit and control the sale of "reptiles of concern" (ROCs), which include Burmese pythons, African rock pythons, amethystine pythons, reticulated pythons, green anacondas, and Nile monitors:

- Owners of ROCs must purchase a $\$ 100$ annual permit.

- ROCs greater than two inches in diameter must be identified by an implanted microchip.

More information about regulations, and online application forms, can be found at:

MyFWC.com/nonnatives/RuleRegs.html

\section{What You Can Do to Help Prevent the Spread of Invasive Snakes}

- Discourage friends from keeping giant snakes as pets. If you or someone you know wants an exotic pet, do your research first and avoid impulse buys.

- If you or someone you know can no longer care for an exotic pet, find someone who can. Don't let it loose!

- Learn to identify Florida's native snakes and tell them apart from exotics.

- Report sightings of free-ranging pythons by calling the USNPS Python Line: 305-815-2080 or the Keys Python Line: 1-888-I've Got 1 (1-888-483-4681).

- To request removal of a nuisance python or an unwanted pet reptile in Miami-Dade County, call the Fire Rescue Department: 786-331-4454

- Learn more about nonnative species and Pet Amnesty Days at myfwc.com/nonnatives.

- Learn more about invasive species and download educational materials such as the "Don't Let It Loose Guide” at floridainvaders.org.

University of Florida researcher Mike Rochford with captured Burmese python

Photo: Jason Folt, University of Florida 


\section{Authors}

Rebecca G. Harvey ${ }^{1}$, Matthew L. Brien ${ }^{1}$, Michael S. Cherkiss ${ }^{1}$, Michael Dorcas ${ }^{2}$, Mike Rochford ${ }^{1}$, Ray W. Snow ${ }^{3}$, and Frank J. Mazzotti ${ }^{1}$

${ }^{1}$ University of Florida, Fort Lauderdale Research \& Education Center, Davie, FL

${ }^{2}$ Department of Biology, Davidson College, Davidson, NC

${ }^{3}$ South Florida Natural Resources Center, Everglades National Park, Homestead, FL

\section{Literature Cited}

Branch, W. R. and H. Erasmus. 1984. Captive breeding of pythons in South Africa, including details of an interspecific hybrid (Python sebae natalensis $\mathrm{x}$ Python molurus bivittatus). Journal of the Herpetological Association of Africa 1984(30):1-10.

Carmichael, P. and W. Williams. 2006. Florida's Fabulous Reptiles and Amphibians. Tenth edition. Hawaiian Gardens, CA: World Publications. 121 pp.

Colvin, B. A., M. W. Fall, L. A. Fitzgerald, and L. L. Loope. 2005. Review of brown tree-snake problems and control programs: report of observations and recommendations. Report to Office of Insular Affairs, Honolulu, Hawaii.

Dorcas, M. E. and J. D. Willson. in press. Innovative methods for studies of snake ecology and conservation. In Snakes: Applied Ecology and Conservation, edited by S. Mullin and R. Seigel. Ithaca, NY: Cornell University Press.

Ernst, C. H. and G. R. Zug. 1996. Snakes in Question. Washington, DC and London: Smithsonian Institution Press. pp. 91-169.

Lederer, G. 1956. Fortpflanzungsbiologie und entwicklung von Python molurus molurus (Linné) und Python molurus bivittatus (Kühl). Die Aquarien- Und Terrarien-Zeitschrift 9:243-248.

Meshaka, W. E., W. F. Loftus, and T. Steiner. 2000. The herpetofauna of Everglades National Park. Florida Scientist 63(2):84-102.

Minton, S. A. and M. R. Minton. 1973. Giant Reptiles. New York: Charles Scribner's Sons. pp. 198-227.

National Research Council. 2005. Re-engineering Storage in the Everglades: Risks and Opportunities. Washington, DC: National Academies Press.

Pope, C. H. 1961. The Giant Snakes. New York: Alfred A. Knopf.

Reed, R. N. 2005. An ecological risk assessment of nonnative boas and pythons as potentially invasive species in the United States. Risk Analysis 25(3):753-766.

Snow, R. W., M. L. Brien, M. S. Cherkiss, L. Wilkins, and F. J. Mazzotti. 2007a. Dietary habits of Burmese python, Python molurus bivittatus, from Everglades National Park, Florida. Herpetological Bulletin 101:5-7.

Snow, R. W., K. L. Krysko, K. M. Enge, L. Oberhofer, A. WarrenBradley, and L. Wilkins. 2007b. Introduced populations of Boa constrictor (Boidae) and Python molurus bivitattus (Pythonidae) in southern Florida. pp. 416-438 in The Biology of Boas and Pythons, edited by R. W. Henderson and R. Powell. Eagle Mountain, UT: Eagle Mountain Publishing.

Wall, F. 1921. Ophidia Taprobanica; or, The snakes of Ceylon. Colombo: H.R. Cottle, govt. printer. pp. 48-69.

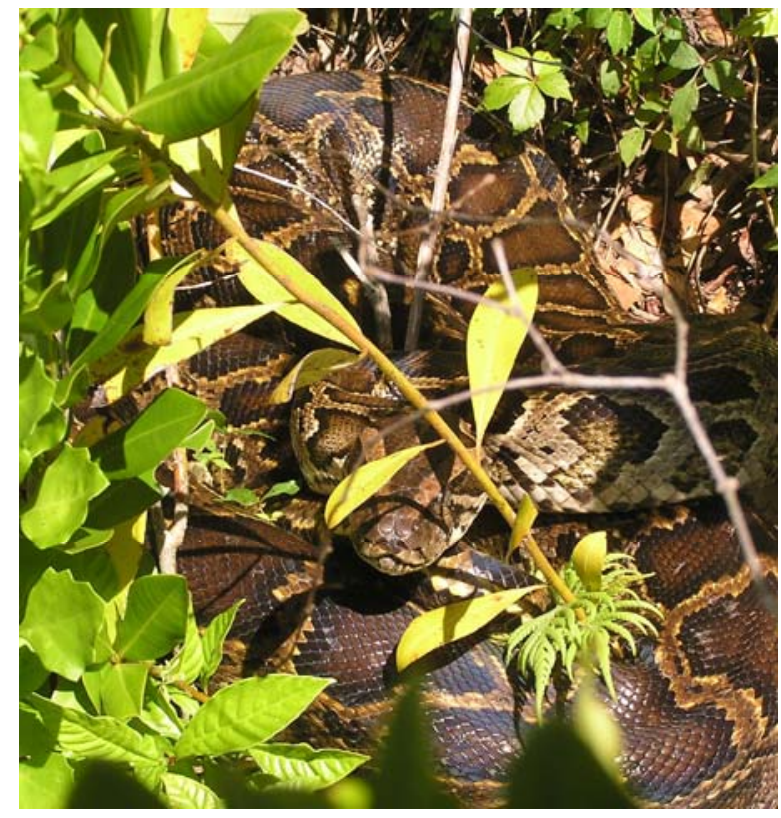

Burmese python in vegetated habitat Photo: Mike Rochford, University of Florida

\section{For more information contact:}

Frank J. Mazzotti University of Florida Fort Lauderdale Research \& Education Center 3205 College Ave., Davie, FL 33314

Email: fjma@ufl.edu

http://crocdoc.ifas.ufl.edu/

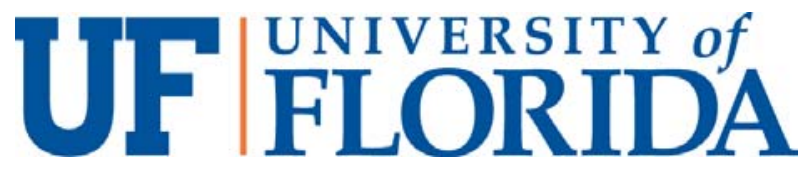




\section{Footnote}

1. This document is WEC242, one of a series of the Department of Wildlife Ecology and Conservation, Florida Cooperative Extension Service, Institute of Food and Agricultural Sciences, University of Florida. First published: April 2008. Please visit the EDIS Web site at http://edis.ifas.ufl.edu.

The Institute of Food and Agricultural Sciences (IFAS) is an Equal Opportunity Institution authorized to provide research, educational information and other services only to individuals and institutions that function with non-discrimination with respect to race, creed, color, religion, age, disability, sex, sexual orientation, marital status, national origin, political opinions or affiliations. For more information on obtaining other extension publications, contact your county Cooperative Extension service.

U.S. Department of Agriculture, Cooperative Extension Service, University of Florida, IFAS, Florida A. \& M. University Cooperative Extension Program, and Boards of County Commissioners Cooperating. Larry Arrington, Dean.

\section{Copyright Information}

This document is copyrighted by the University of Florida, Institute of Food and Agricultural Sciences (UF/IFAS) for the people of the State of Florida. UF/IFAS retains all rights under all conventions, but permits free reproduction by all agents and offices of the Cooperative Extension Service and the people of the State of Florida. Permission is granted to others to use these materials in part or in full for educational purposes, provided that full credit is given to the UF/IFAS, citing the publication, its source, and date of publication. 